\title{
Statyba
}

\section{PROFESSOR ALGIRDAS ČIŽAS AS FAMOUS SCIENTIST AND EDUCATOR}

\section{J. Atkočiūnas}

To cite this article: J. Atkočiūnas (1999) PROFESSOR ALGIRDAS ČIŽAS AS FAMOUS

SCIENTIST AND EDUCATOR, Statyba, 5:3, 161-165, DOI: 10.1080/13921525.1999.10531456

To link to this article: https://doi.org/10.1080/13921525.1999.10531456

册 Published online: 26 Jul 2012.

Submit your article to this journal $\widetilde{ }$

山 Article views: 68 
Profesoriui A. Čižui - 70 metụ

\section{PROFESORIUS ALGIRDAS ČIŽAS - ŽYMUS MOKSLININKAS IR PEDAGOGAS}

\section{J. Atkočiūnas}

Vilniaus Gedimino technikos universiteto Medžiagu atsparumo katedros profesorius, habilituotas daktaras, Švietimo ir mokslo ministerijos Studijų kokybès vertinimo centro direktorius Algirdas Čižas pasitinka garbinga 70 melu, kupinu mokslinès ir pedagoginés veiklos, jubilieju.

Algirdas Eduardas Čižas gime 1929 metu rugsèjo 16 d. Anykščiuose - tèvų namas stovejjo už šimto metrų nụo rašytojo $\mathrm{A}$. Vienuolio sodyboje rymančios Baranausko klètelès... Tèvai turejo 14 ha ükị. Tačiau Algirdo vaikystès takai išbėgioti ir Žemaitijoje: keliolika metu ūkis buvo nuomojamas, nes tẻvas tarnavo Lietuvos geležinkelių policijoje (Anykščiuose, Tauragèje, Pagègiuose, Lūšèje). Dèl patirtos tarnyboje traumos $1940 \mathrm{~m}$. kovo mèn. tévas buvo išleistas $i$ pensiją ir vèl èmè ūkininkauti savo žemèje. Todel gimnaziją Algirdas 1947 metais baigè jau Anykščiuose gavo brandos atestatą su sidabro medaliu. Sovietinè valdžia pensijos mokejjimus tèvui buvo jau nutraukusi, 1948 m. ūkis tapo kolūkio dalimi. Šiame kolūkyje tèvas iš pradžiu dirbo sąskaitininku, vèliau sodininku... O sodas šliejosi prie Antano Vienuolio sodybos! Verta tai issidèmèti - galbūt iškiliojo anykštèno asmenybè lèmé, kūrybai palankus Anykščiu krašto grožis kreipè Algirdo sielą literatūros, architektūros, teatro ir apskritai meno link? Matyt, dèsninga, jog buvo nutarta studijuoti architektūrą. Deja, pavèlavo nunešti atestatą (ilgokai ministerijoje buvo sprendžiama, koks jis turètụ būti - su aukso ar sidabro raidèmis), todèl teko pasirinkti iš pradžių kelių statybą (ten buvo dar likę vietu), véliau - pramoninę ir civilinę statybą. Studijuodamas Kauno universiteto (vèliau - Kauno politechnikos instituto) Statybos fakultete pusę laiko skyrè tenisui (II atskyris), šachmatams (II atsk.), šaškèms (I atsk.), meno saviveiklai (dramai). Antrame kurse net panūdo lygia greta pastudijuoti ir dramos studijoje prie Kauno teatro. Tačiau prièmimo komisijos pirmininko Łtikintas, jog aktorystè - tai ne profesija, atsisakè savo ketinimo. Užtat abi svajones vèliau su kaupu igyvendino sūnūs - Dainius tapo architektu, Tauras - akto-

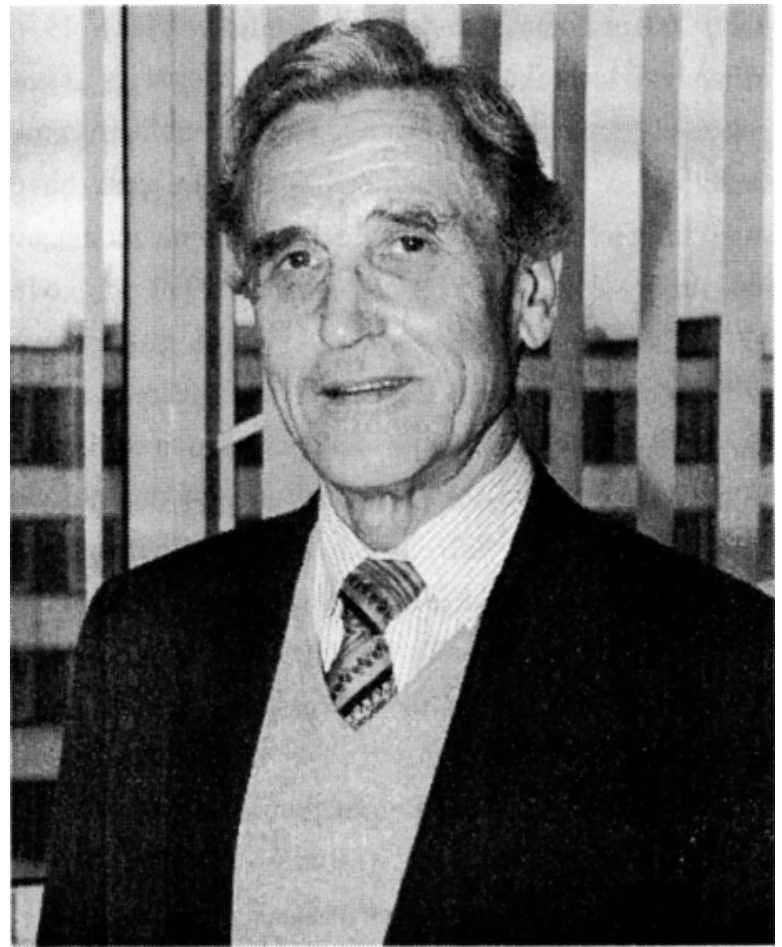

riumi. Su savo žmona Janina Algirdas irgi susipažino per sportą ir studentišką meno saviveiklą. Vede 1952 m., jau baigdamas studijas. Kadangi žmona buvo pedagogé, jaunasis pramoninès ir civilinès statybos inžinierius nebuvo išsiųstas iš Lietuvos (grèsè paskyrimas i Alma Atą, po to - i Oriola).

1953 metais Algirdas Čižas pradejo dirbti Vilniuje Valstybinès politinès ir mokslinès literatūros leidyklos redaktoriumi. Teko organizuoti pirmaja techninès literatūros redakcija, būti jos vedèju. 1957-1958 m. dirbo Valstybiniame statybos ir architektūros reikalu komitete - organizavo pirmają nuolatinę statybos parodą (isikūrusią Šv. Mykolo bažnyčioje, joje vèliau isteigtas Architektūros ir statybos muziejus). 1958-1964 m. dirbo Lietuvos mokslu akademijos Enciklopedijos redakcijoje - buvo enciklopedijų mokslinès redakcinès tarybos narys. Ir dabar yra rengiamos Technikos enciklopedijos vyriausiojo redaktoriaus pavaduotojas.

Nuo 1963 metų A. Čižo darbas jau susijęs su aukštaja mokykla, tuomet - Kauno politechnikos instituto Vilniaus filialu. Abi disertacijos, mokslo laips- 
niai, pedagoginiai vardai - viskas čia, toje pačioje mokykloje, kurios vardas nuolat keitèsi - VISI, VTU, VGTU. $1964 \mathrm{~m}$. istojo i KPI aspirantūra, parašè ir 1967 m. apgynè technikos mokslu kandidato disertacija ,Matematinio programavimo metodu taikymas tampriosioms-plastinèms sijoms ir rèmams skaičiuoti ribojant deformacijas“. Pirma laiko baigęs aspirantūrą, iškart èmé dirbti KPI Vilniaus filialo vyresniuoju dèstytoju, o nuo $1969 \mathrm{~m}$. - docentu (jau isteigtame Vilniaus inžineriniame statybos institute - VISI). 1974 m. apgyné technikos mokslu daktaro disertaciją "Tampriuju-plastiniu tiesiškai stiprèjančiu optimalių sistemu skaičiavimo teorija ir metodai“. $1977 \mathrm{~m}$. jam buvo suteiktas profesoriaus vardas, o Lietuvos nusipelniusio mokslo ir technikos veikèjo - 1979. 1993 m. kovo 17 d. Lietuvos mokslo taryba A. Čižui nostrifikavo habilituoto daktaro mokslo laipsni ir profesoriaus vardą. 1976-1994 m. konkurso tvarka jis buvo renkamas Vilniaus inžinerinio statybos instituto bei pertvarkyto Vilniaus technikos universiteto (VTU) Medžiagu atsparumo katedros vedeju, o 1980-1987 m. buvo išrinktas dar ir Statybos fakulteto dekanu, $1989 \mathrm{~m}$. VISI tarybos pirmininku, po to - Universiteto laikinosios tarybos pirmininku.

Prof. A. Čižas visada domèjosi (ir domisi!) aukštojo mokslo organizavimu ir studiju kokybès problemomis. $1989 \mathrm{~m}$. jis buvo išrinktas i Sajūdžio Seimą, vadovavo jo Švietimo komisijai, vèliau koordinavo keliu aukštaji mokslą reglamentuojančiu valstybiniu dokumentų projektu rengimą. Yra Lietuvos mokslo tarybos Mokslininku kvalifikacijos komisijos ekspertas, šios komisijos pirmininko pavaduotojas. Nuo 1995 m., vis dar tebedirbdamas Vilniaus Gedimino technikos universiteto (VGTU) Medžiagu atsparumo katedros profesoriumi, pradejo vadovauti Švietimo ir mokslo ministerijos isteigtam Studiju kokybès vertinimo centrui. Aktyviai dalyvavo tarptautiniuose "Phare" projektuose, skirtuose studiju kokybei gerinti ne tik Lietuvoje, bet ir kitose Rytų ir Vidurio Europos šalyse (buvo projektą vykdžiusio tarptautinio konsorciumo vadybinès grupès narys). $1998 \mathrm{~m}$. koordinavo Baltosios knygos "Lietuvos aukštasis mokslas“ projekto rengimą buvo vienas iš šio projekto autorių. Dabar - aktyvus naujojo istatymo, reguliuosiančio aukštaji mokslą, projekto rengimo dalyvis. Per visa pedagoginès veiklos laikotarpi rūpinosi aukštojo mokslo pedagogikos problemomis, studiju kokybe.

Prof. A. Čižas yra paskelbęs arti šimto mokslinių publikaciju konstrukciju mechanikos, optimizacijos me- todụ ir aukštojo mokslo pedagogikos klausimais [A 1-22], [B 1-9], [C 1-6], [D 1-3]. Tačiau daugiausia - iš konstrukciju mechanikos, ypač optimalių konstrukciju skaičiavimo metodikos [A 1-22]. Pirmoji moksliné šios srities publikacija „Tiesinio programavimo metody taikymas tampriosioms ir plastinèms sistemoms skaičiuoti pagal ribines deformacijas (pagal eksploatacinę galia)“ [A 2] pasirodè Kauno politechnikos instituto Vilniaus filialo išleistame leidinyje. Taigi savo darbuose A. Čižas plačiai taikè matematini programavimą. Deformuojamos idealiai tampriosios ir plastines konstrukcijos optimizacijos uždavinys buvo nagrinejjamas pagal dvi formuluotes - statinę ir kinematinę. Prof. A. Čižas èmé nagrinèti sistemas, kuriamas iš netiesiškai deformuojamy tampriuju ir plastiniu medžiagu [A 4-5], parengè tiesiškai stiprèjančiu sistemu skaičiavimo ir optimizavimo metodus [A 7, 10, 1], 13], pradéjo vietoj idealaus plastinio šarnyro lenkiamame strype tirti plastines deformacijas realaus skerspjūvio strype [A 12, 15, 21]. Drauge su savo mokiniais tyrè konkrečius taikomuju konstrukciju mechanikos uždavinius: su A. Krutiniu - konstrukciju ant deformuojamo pagrindo skaičiavimą su V. Kamaičiu baigtiniu elementu metodo taikymą [A 8], su D. Džankarašviliu - iš anksto itemptų vantinių sistemy skaičiavimą, su S. Stupaku ir J. Medzviecku - deformuojamų atramų itaką konstrukcijai [A 18, 20], su S. Stupaku - realaus elementụ asortimento naudojimą [A 22], su M. Šukšta - kartotinès-kintamosios apkrovos itaka, su A. Komka - vamzdiniu kompozitiniu elementu deformavimą [A 19]. Visi profesoriaus mokiniai parengè ir apgyne daktaro disertacijas.

Prof. A. Čižas, kaip pripažintas Lietuvos konstrukcijų mechanikos specialistas, yra oponavęs nemaža disertaciju, recenzavęs daug moksliniu straipsniu ir metodinių leidinių. Aktyviai bendradarbiauta su Veimaro aukštaja architektūros mokykla (Hochschule für Architektur und Bauwesen Weimar-Universität), dabar tą bendradarbiavimą tęsia VGTU Statybinès mechanikos ir medžiagu atsparumo katedros. Kai Vilniuje vykdavo tarptautinès konferencijos „Optimizacijos ir patikimumo problemos statybinèje mechanikoje“ (1975, 1979 , 1983, 1988 m.), A. Čižas buvo organizacinio ir mokslinio komitetų vienas iš vadovu. Jis yra tarptautinių konferenciju „Naujos statybinès medžiagos, konstrukcijos ir technologijos“, kurios vyksta nuo 1991 metu Vilniuje, mokslinio komiteto narys ir VGTU Statybinès mechanikos katedros kuruojamos sekcijos „Konstrukciju optimizavimas ir nauji skaičiavimo metodaj" vie- 
nas iš moksliniu vadovų. Profesorius skaité pranešimus daugelyje tarptautiniu mokslinių konferenciju (Rusijoje, Lenkijoje, Italijoje, Anglijoje, JAV ir kitur).

"Lietuvos mechanikos rinkinio" (LMR) beveik trisdešimties metụ istorija (išèjo 32 numeriai) glaudžiai susijusi su visa mechanikos mokslo raida Lietuvoje. Visą laiką prof. A. Čižas buvo LMR redakcijos kolegijos sekretorius ir aktyviausias redaktorius. Net ir tada, kai buvo reikalaujama kiekvienam mokslo darbu rinkiniui sugalvoti temini pavadinimą, atsakomojo sekretoriaus A. Čižo pastangomis LMR serija nenutrūko. Daugelis Lietuvos mokslininkų buvo nuolatiniai LMR autoriai, jie aprépe jvairias mechanikos tyrimu šakas. Leidinys spausdinamas rusu kalba su lietuviškomis ir angliškomis santraukomis. $1994 \mathrm{~m}$. anglų kalba išleistas rinkinys (Nr. 33) jau rodé naują Lietuvos mokslininkų darbo krypti. Tačiau Lietuvos mokslo tarybai reorganizavus moksliniụ žurnalu leidyba, ,Lietuvos mechanikos rinkinys" nustojo èjęs. Dabar mechanikos krypties mokslinių tyrimų rezultatai skelbiami žurnaluose "Statyba" ir "Mechanika". Prof. A. Čižas yra šiq žurnalų redakciju kolegiju narys. Jis yra aktyvus mokslo bei technikos terminologijos tvarkytojas [D 13], Valstybinès lietuviu kalbos komisijos prie Lietuvos Respublikos Seimo narys.

Ilgametis Medžiagu atsparumo katedros vadovas prof. A. Čižas vadovavo ir medžiagu atsparumo (medžiagu mechanikos) destymo metodikos tobulinimo darbams. Prof. A. Čžas - Lietuvos aukštųju mokyklụ studentiškų medžiagu atsparumo olinpiadų ¡kvèpèjas ir organizatorius. Kasmet jis sukuria vis naujas užduotis šioms olimpiadoms ir džiaugiasi, kad vis atsiranda studentų, sugebančių sèkmingai išspręsti net ir sudètingus uždavinius. Profesoriui itin malonu, jog tarp geriausiu medžiagu atsparumo mokovu dažniausiai yra būtent VGTU atstovai.

Nèra paprasta vienu metu būti ir geru mokslininku, ir pavyzdingu pedagogu, tačiau prof. A. Čižui tai pavyksta. Idomios ir studentų mégstamos yra jo lietuviu ir anglų kalbomis skaitomos konstrukciju mechanikos paskaitos. Nelengvai išmokstamą medžiagu atsparumo discipliną jis išaiškina vaizdžiai, suprantamai. Tiesa, kartais egzaminy metu būna griežtokas, nemègsta nusirašinejančių (jo nuomone, studentas turi būti sqžiningas, mąstantis ir linksmas - tikras savianalizès idealas!). Pas profesorių iš pirmo karto mažai kas išlaiko egzaminą. Juokaujame: ką gi, taip ir turi būti, juk prof. A. Čižas -- Studijų kokybès vertinimo centro direktorius!
Naujas mokslines idejjas prof. A. Čižas perteikia studentams, magistrantams, būsimiesiems inžinieriams [C 2, 5, 6]. Apskritai knygas A. Čižas pradejo rašyti gana anksti. Pirmoji jo knyga „Šriftai ir ju naudojimas brěžiniuose, plakatuose, sienlaikraščiuose“ (su K. Dockumi) išleista 1958). Kiek vèliau - „Aiškinamasis tekstilès terminų žodynas" (su A. Jurevičiumi, 1962, 1 d.). Keliolika knygy (daugiausia - tai techninè literatūra) išversta iš rusu kalbos. Net ir mègstamas laisvalaikio užsièmimas - mokslinès ir techninès mokslo populiarinimo literatūros vertimas ir redagavimas. Profesoriaus lentynoje - daugybè jo redaguotu knygu. Jam teko redaguoti ir savo buvusiu profesoriu vadovèlius (A. Rozenbliumo „Mürinès konstrukcijos“, 1956; J. Mikucko „Statybos pagrindai“, 1957) ir žinomu architektų A. Spelskio bei J. Baršausko monografijas.

Visuomet galejai ir gali kreiptis i prof. A. Čiža patarimu, paramos, rengdamas straipsni ar redaguodamas disertacija. „Man gera, kai pajuntu, kad kam nors kitam gera padariau“, - kartais prasitaria profesorius. Tai optimistas, tikintis šviesia žmogaus prigimtimi, nesenstančiais moralès dessniais. Net ir tada, kai lieka nesuprastas... Gal tyrieji Šventosios vandenys Algirdo sieloje nuskaidrino svarbiausius jo gyvenime kelrodžius žodžius: Lietuva, Pažinimas, Kūryba, Šeima...

Visiems mums malonu, jog pasiekęs gyvenimo brandą prof. A. Čižas išliko aktyvus daugelyje gyvenimo sričių. Linkime Jubiliatui Algirdui Čižui geros sveikatos, kürybinès sèkmès ir laimès.

\section{Svarbiausios A. Čižo publikacijos}

\section{A - MECHANIKA, OPTIMIZACIJA}

1. А. Чижас, Методы решения упруго-пластических одномерньх систем // Строительная механика: Докл. XV научн.-техн. конф. Вилынюс, 1965, с. 5-24.

2. А. Чижас. Применсние методов линейного программирования при расчете упруго-пластических систем по предельным деформациям (по эксллуатационной способности) // Строительная механика: Докл. XVI научн.-техн. конф. Каун. политехн. ин-та. Вильнюс, 1966, с. 24-41

3. А. Чижас. Математическая модель задачи расчета предварительно напряженных упруго-пластических стержневых систем // Литовский механический сборник, 1968, № $1(2)$, с. $90-99$

4. А. Чижас. Расчет стержневой системы при нелинейном законе деформирования // Литовский механический сборник. 1970, № 1(6), с. 107-121.

5. А. Чижас, ПІ. Баублис. Реализация на ЭВМ расчета изикбаемых стержневых систем при нелинейном законе деформирования стержней // Литовский механический сборник, 1971, № 1(8), с. 105-110. 
6. А. Чижас. К решению некоторого класса нелинейных задач стохастического программирования в жесткой постановке // Литовский механический сборник, 1972, № $1(10)$, c. 15-20.

7. А. Чижас. К расчету упруго-пластических упрочняющихся одномерных систем // Строительная механика и расчет сооружений, 1973, № 2, с. 16-20.

8. А. Чижас, В. Камайтис. Метод равновесных конечных элементов в задачах строительной механики // Литовский механический сборник, 1973, № 1(12), с. 105-114.

9. А. Чижас. Учет местной разгрузки пластических зон в расчетах пластических систем // Литовский механический сборник, 1973, № 1(12), с. 115-119.

10. А. Чижас. Аппроксимация закона развития пластической деформации при упрочняюшемся материале // Литовский механический сборник, 1974. № $1-2(14-15)$, c. $77-81$

11. A. Čižas. On Optimal Design of Strainhardening Structures // IUTAM, Optimization in Structural Desing, Symposium Warsaw. Springer-Verlag, Berlin Heidelberg New-York, 1975 , p. 555-563

12. А. Чижас. Алгоритм расчета изгибаемой стержневой упруго-пластической системы с учетом реальной формы сечения // Литовский механический сборник, 1976. № $1(16)$, c. 104-113.

13. А. Чижас. Математическая модель задачи проектного расчета оптимальной трехслойной изгибаемой пластинки с линейно упрочняющимися внешними слоями // Wissenschaftliche Zeitschrift der Hochschule für Architektur und Bauwesen, 23, H. 3. Weimar. 1976, S. 230232.

14. А. Чижас, Д. Г. Джанкарашвили. Алгоритм решения задачи расчета предварительно напряженной вантовой системы с одним узлом за пределом упругости // Литовский механический сборник, 1977, № 2 (18), c. 75-85.

15. А. Чижас. Алгоритм дискретного программирования для оптимизации стержневых систем при заданном ассортименте стержней // VIII Internationaler Kongres über Anwendungen der Mathematik in den Ingenieurwissenschaften. Berichte, 1. Weimar, 1978, S. $171-176$.

16. А. Чижас. Жесткостные ограничения в упругопластическом расчете при повторно-переменном воздействии и линейном напряженном состоянии // Литовский механический сборник, 1978, № 19, с. 24-33.

17. А. Чижас. Билинейная аппроксимация законов поведения податливых опор деформируемых твердых тел // Литовский механический сборник, 1980, №2 21, с. 20-24.

18. А. Чижас, С. И. Ступак. Влияние характера податливости опор на напряженно-деформированное состояние и оптимальность стержневой системы // Изв. вузов. Строительство и архитектура, 1982, № 7, с. 3942.

19. А. П. Чижас. Определение деформированного состояния упруго-пластического стержня кольцевого сечения // Литовский механический сборник, 1983, № 25 , с. $47-58$.

20. Ю. И. Медзвецкас, А. П. Чижас. Определение оптимальной податливости опор неразрезной упругой балки // Литовский механический сборник.
Исследования прочности и динамики конструкций 1986, № 28, c. $72-81$.

21. A. Čižas. Behaviour of beams with spreads of plastic strains // Lithuanian Journal of Computational Mechanics, Vol. 33, 1994, p. 92-98.

22. A. Čižas, S. Stupak. Optimal discrete design of elastoplastic structures // Discrete Structural Optimization. Springer-Verlag, 1994, p. 200-208.

\section{B - AUKŠTASIS MOKSLAS}

1. A. Čižas. Darbo apskaita ir jo vertinimas aukštojoje mokykloje // Mokslas ir technika, 1979, Nr. 9, p. 34-35.

2. A. Čižas. Aukštos kvalifikacijos specialistų rengimas Lietuvos ateičiai // Mokslinès konferencijos „Tautinè aukštosios mokyklos koncepcija ir Kauno universitetas", ivykusios Kaune $1989 \mathrm{~m}$. balandžio 26-28 d., medžiaga. Kaunas, 1989, p. 7-9.

3. A. Čižas. Aukštasis mokslas pertvarkant švietima // Tautine mokykla, 1989, Nr. 9, p. 4-6.

4. A. Čižas. Lithuanian steps towards the Baltic family of universities // Abstracts of the Conference „Baltic Family". Kaunas, 1990, p. 43-44.

5. A. Čižas. New Universities in Lithuania and their problems // New universities and regional context Acta universitatis upsaliensis, Uppsala Studies in Education 56, Uppsala, 1994, p. 199-204.

6. A. Čižas. Lithuania // Multilingual Lexicon of Higher Education, Vol. 2. K. G. Saur, München, 1996, p. 127143

7. A. Čižas. Quality assessment in smaller countries: problems and Lithuanian approach // Higher Education Management. March 1997, Vol. 9, No 1, p. 43-48.

8. A. Čžžas. Quality Assessment of Lithuanian Higher education // Global J. of Enginneering education, Australia. 1997, Vol. 1, No 3, p. 281-284.

9. A. Čižas. Studijụ programų kokybès vertinimo strategija // Konferencijos „Lietuvos mokslas ir pramone XXI amžiaus technologijas pasitinkant", ivvkusios $1999 \mathrm{~m}$. Kaune, medžiaga. Kaunas: Technologija 1999, p. 88-91.

\section{C - MEDŽIAGU ATSPARUMO METODIKA}

1. A. Čižas. Tempimo-gniuždymo uždaviniu sprendimas. Metodikos nurodymai / VISI. Vilnius, 1974. 48 p.

2. A. Čižas, V. Viršilas, J. Žekevičius. Aiškinamasis medžiagu atsparumo uždavinynas. Vilnius: Mokslas, 1985. 279 p.

3. А. Чижас, К. Виславичюс. Применение ЭВМ для совершенствования организации учебного процесса в курсе «Сопротивление материалов» // Некоторые методические вопросы интенсификации учебного процесса в вузе. Вильнюс, 1986, с. 48-53.

4. A. Čižas. Inžinerinio mąstymo igūdžiai ir bendrosios technikos disciplinos // Pedagogika, T. 22. Aukštosios technikos mokyklos pedagogikos problemos. Vilnius: Mokslas, 1987 , p. 26-35.

5. A. Čižas. Tempimas ir gniuždymas. Paskaitų ciklas. Vilnius, 1989. $51 \mathrm{p}$

6. A. Cižas. Medžiagu atsparumas (Konstrukciju elementu mechanika). Vilnius: Technika, 1993. 424 p. 


\section{D - TERMINOLOGIJA, KALBA}

1. A. Čižas. Sistemingai tvarkyti techninę terminologiją // Mokslas ir technika, 1958. Nr. 6-7, p. 49-50.

2. A. Čižas, A. Jurevičius. Aiškinamasis tekstilès terminụ žodynas. V.: Resp. moksl.-techn. inform. ir propagandos inst., 1962. $99 \mathrm{p}$.

3. A. Čižas. Tebūnie išklausyta ir kita pusè: Atsiliepimas i V. Būdos str. ..nžinierius ir kalba“ // Inžinerija, 1975.

Iteikta 19990628

\section{PROFESSOR ALGIRDAS ČIŽAS AS FAMOUS SCIENTIST AND EDUCATOR}

\section{J. Atkočiūnas}

\section{S u m m a r y}

Algirdas Eduardas Čižas is Professor of the Department of Strength of Materials, Director of the Lithuanian Centre for Quality Assessment in Higher Education.

Prof A.Čižas was born on September 16, 1929 in a picturesque Lithuanian locality, Anykščiai. In 1952 he graduated from Kaunas Polytechnic Institute (Faculty of Civil Engineering). In 1953-57 editor and head of the Division of Technical Literature in a publishing house in Vilnius, in 1959-64 editor of Lithuanian encyclopedias. In 1967 a Doctoral student, then teacher, Associated Professor, since 1977 full Professor at the Vilnius Civil Engineering Institute (later Vilnius Technical University). In 1980-87 Dean of Civil Engineering Faculty, since 1995 Director of the Centre for Quality. More than 100 scientific publications on higher education problems and structural mechanics, optimisation methods. A.Čižas has introduced restrictions of stiffness, influence of a cross-sectional shape and a strain-hardening factor into optimisation theory of structural mechanics. The first paper "Application of mathematical programming methods for analysis of elastic-plastic structures with restricted deformation" (in Russian) was published in "Statybine mechanika" (Structural mechanics) issued by the Kaunas Polytechnic Institute in 1966. A.Čižas reported his research results at international conferences in Russia, Poland, Italy, United Kingdom, USA, etc.

More than 25 years of publishing "Lithuanian Proceedings in Mechanics" ("Lietuvos mechanikos rinkinys)" (1968-94) are related to the development of Lithuanian research in mechanics. During the whole period A.Čižas was a managing editor of the journal. All the papers in volumes 1-32 of the LPM were published in Russian with Lithuanian and English summaries. After integration of the journals, results of research on mechanics are published in "Mechanika" (Mechanics) and "Statyba" (Civil Engineering). A.Čižas is a member of editorial boards of both journals, an author of the textbook "Strength of Materials. Mechanics of Structural Members" (1993, in Lithuanian), a co-author of the textbook "Problems on Strength of Materials with Comments" (1985). He has translated (from Russian into Lithuanian) more than ten books.

Prof A.Čižas is a coordinator of drafting several legislative acts for higher education. Member of the Seimas of Sajūis (1988-90), member of the Lithuanian State Language Committee at the Seimas of the Republic of Lithuania, expert of Science Council of Lithuania.

Juozas ATKOČIŪNAS. Doctor Habil, Professor. Head of the Dept of Structural Mechanics, Vilnius Gediminas Technical University (VGTU). Sauletekio al. 11, 2040 Vilnius, Lithuania. E-mail: Juozas.Atkociunas@st.vtu.lt

Civil engineer, 1967. Dr Eng (structural mechanics, 1973) Dr Habil (mechanics, 1996). Research interests: structural and computational mechanics, applied mathematical programming, analysis and optimisation of dissipative structures under repeated-variable loading. 